Noncompliance

\section{in randomized controlled}

\section{trials}

Catherine Hewitt and colleagues ${ }^{1}$ have given an excellent brief account of the effect of noncompliance on the analysis of randomized controlled trials. We would like to add a few more points to make the discussion more complete.

Noncompliance can seriously decrease study power, ${ }^{2}$ resulting in widely varying estimates of the sample size required for a study. ${ }^{3}$ Noncompliance is thus a significant issue to be considered when planning trials involving long-term therapies. Moreover, the analysis of results for patients receiving treatment can be biased in situations in which participants decline treatment because they cannot afford to pay for their drugs, if they are not provided free of charge. ${ }^{4}$ Incorporation of patient preferences into the randomization process will also bias the results. ${ }^{5}$ With these practical issues in mind, it would be an interesting exercise to compare the results of well-designed observational studies with those of randomized controlled trials.

\section{Jeevan P. Marasinghe}

Registrar in Obstetrics and

Gynecology

Faculty of Medicine

University of Peradeniya

Peradeniya, Sri Lanka

A.A.W. Amarasinghe

Psychiatrist

McDonough, Ga.

\section{REFERENCES}

I. Hewitt CE, Torgerson DJ, Miles JNV. Is there another way to take account of noncompliance in randomized controlled trials? CMAJ 2006;175(4): 347 .

2. Snapinn SM, Jiang Q, Iqlewicz B. Informative noncompliance in endpoint trials. Curr Control Trials Cardiovasc Med 2004;5(I):5

3. Freedman LS. The effect of partial noncompliance on the power of a clinical trial. Control Clin Trials I990;II(3): I57-68.

4. De Silva HA, Pathmeswaran A, Gunatilake SB. Efficacy of rivastigmine on activities of daily living in Sri Lankan patients with Alzheimer Disease and on improving caregiver burden: a prospective study. Ceylon Med J 2005;50(3):106-9.

5. Lambert MF, Wood J. Incorporating patient preferences into randomized trials. J Clin Epidemiol. 2000;53(2):163-6.

DOI:I0.1503/cmaj.ro6or89

\section{Novice drivers with}

\section{attention-deficit}

\section{hyperactivity disorder}

The recent $C M A J$ lead editorial on the high rate of injuries and deaths among youthful drivers is long overdue. ${ }^{1}$ It focuses our attention on potentially modifiable human factors in this important public health epidemic. ${ }^{2}$ The latest edition of the CMA driver's guide includes changes concerning the safety of drivers with attention-deficit hyperactivity disorder (ADHD). ${ }^{2}$

ADHD was first mentioned as a reportable condition in the previous edition of the handbook. ${ }^{3}$ In the 2006 edition, physicians are advised to consider treating novice drivers with ADHD with long-acting stimulants, on the basis of a recent meta-analysis examining the effects of a variety of medications used to treat ADHD. ${ }^{4}$ The conclusion from this meta-analysis was that young drivers with ADHD show a normalization of dysfunctional driving behaviours on a driving simulator and during on-the-road driving when they receive treatment with long-acting methylphenidate compared with treatment with other stimulants and nonstimulants.

To our knowledge this is the first time that clinical research has demonstrated that medications improve driving performance in a vulnerable psychiatric population. We applaud the CMA's decision to incorporate evidence-based findings in their new handbook; recommendations in previous editions were based on the consensus opinion of an expert panel. The new recommendation leads the way for the international public health community to reduce the risks associated with driving for youth with ADHD.

\section{Laurence Jerome}

Adjunct Professor of Psychiatry

University of Western Ontario

London, Ont.

\section{REFERENCES}

I. MacDonald N, Yanchar N, Hebert PC. What's killing and maiming Canada's youth? $C M A J$ 2007; I76(6):737.
2. Canadian Medical Association. Determining medical fitness to operate motor vehicles. CMA driver's guide. $7^{\text {th }}$ ed. Ottawa $(\mathrm{ON})$ : The Association; 2006.

3. Canadian Medical Association. Determining medical fitness to drive: a guide for physicians. 6th ed. Ottawa (ON): The Association; 2000.

4. Jerome L, Segal A, Habinski L. What we know about $\mathrm{ADHD}$ and driving risk: a literature review, meta-analysis and critique. J Can Acad Child Adolesc Psychiatry 2006;15(3):I05-25.

DOI:I0.1503/cmaj.I070042

\section{Organ donation after}

\section{cardiocirculatory death}

The Canadian recommendations for organ donation after cardiocirculatory death advocate confirming the irreversibility of cardiocirculatory arrest by the absence of palpable pulses, blood pressure and respiration during a 5minute period of continuous observation by at least I physician. ${ }^{1}$ This criterion does not fulfill the prerequisite requirement of irreversibility for the determination of death.

First, autoresuscitation (the spontaneous return of circulatory and neurological function), also known as the Lazarus phenomenon, has been reported after more than ro minutes of cardiac electric asystole in humans. ${ }^{2}$ Second, the presence of electrocardiographic activity without blood pressure (i.e., pulseless electric activity or ventricular fibrillation) does not indicate irreversible cessation of mechanical cardiac activity. ${ }^{3}$ Third, the applicability of criteria for organ donation after cardiocirculatory death becomes questionable when artificial circulatory and ventilatory support is resumed after death in order to maintain the viability of abdominal and thoracic organs in potential donors. ${ }^{4,5}$ Extracorporeal circulatory support can lead to the return of neurological function in people who are neurologically intact before cardiac death. ${ }^{6}$ Mechanical occlusion of coronary and cerebral circulation has been used to try to prevent reanimation during the organ procurement process, without substantial evidence for its effectiveness. ${ }^{5}$

The timing involved in cardiocirculatory criteria is arbitrary, and the use of such criteria alone to determine death without simultaneous total cessation of all activity in the donor's brain 
(including the brain stem) during procurement circulatory support will not fulfill the "dead donor rule." 7,8 It may be necessary to abandon the dead donor rule to permit the recovery of transplantable organs after cardiocirculatory death.

\author{
Mohamed Y. Rady \\ Department of Critical Care Medicine \\ Joseph L. Verheijde \\ Department of Physical Medicine and \\ Rehabilitation \\ Mayo Clinic Hospital \\ Phoenix, Ariz. \\ Joan McGregor \\ Bioethics, Policy and Law Program \\ School of Life Sciences and \\ Department of Philosophy \\ Arizona State University \\ Tempe, Ariz.
}

\section{REFERENCES}

I. Shemie SD, Baker AJ, Knoll G, et al. Donation after cardiocirculatory death in Canada. CMAJ 2006;I75 (8 Suppl):Si-S24.

2. Adhiyaman V, Sundaram R. The Lazarus phenomenon. JR Coll Physicians Edinb 2002;32:9-I3.

3. American Heart Association. Management of cardiac arrest. Circulation 2005;II2:IV58-IV66.

4. Institute of Medicine Committee on Non-HeartBeating Transplantation II. The scientific and ethical basis for practice and protocols. Executive summary. Washington (DC): National Academy Press; 2000.

5. Magliocca JF, Magee JC, Rowe SA, et al. Extracorporeal support for organ donation after cardiac death effectively expands the donor pool. J Trauma 2005;58:I095-IIOI.

6. Younger JG, Schreiner RJ, Swaniker F, et al. Extracorporeal resuscitation of cardiac arrest. Acad Emerg Med i999;6:700-7.

7. Menikoff J. The importance of being dead: nonheart-beating organ donation. Issues Law Med 2002;18:3-20.

8. Bernat, J.L. Are organ donors after cardiac death really dead? JClin Ethics 2006;17:122-32.

DOI:I0.I503/cmaj.1060217

\section{Breaking bad news}

I thank medical student Nir Lipsman for his insightful and touching article on the hospital's Family Room. ${ }^{1}$ This room is usually spoken of, if at all, in hushed and sometimes reverent tones, and when one meets with family members and loved ones there, one is generally met with emotions at the polar ends of the emotional spectrum. The physician's information will lead to either complete devastation or utter elation; there is rarely a reaction in between these extremes.
Attending physicians can learn from Lipsman's advice to avoid dancing around the truth, something I have seen happen far too often. When I informed a Family Room full of people that their loved one in the intensive care unit would be paralyzed from the neck down for life, I was met not with sobs and grief, but with questions: "What is the next step? What can we do to help? When can he come home to live with us?" Like Lipsman, I never cease to be amazed by the strength and resilience of these families.

\section{Jeff Blackmer}

Executive Director, Office of Ethics

Canadian Medical Association

Ottawa, Ont.

\section{REFERENCE}

I. Lipsman N. The family room. $C M A J 2007 ; 176(3)$ : 354.

DOI:10.1503/cmaj.1070026

\section{Staffing levels in long-term}

\section{care facilities}

In their recent $C M A J$ commentary, ${ }^{1}$ Kimberlyn McGrail and associates correctly noted that in British Columbia private and not-for-profit providers of long-term care have different staffing levels at their sites. However, these differences are driven not by type of ownership but by health authority funding level. Funding varies from $\$ 130$ to $\$ 190$ per day for each resident even though the facilities care for the same types of clients requiring complex care. With such a wide range in funding, it is expected that there would be differences in staffing levels.

The authors also state that the aggregated superiority of the not-for-profit sector in hospital admission rates was driven by "not-for-profit facilities that were attached to acute care hospitals, were amalgamated to a health authority or had more than one site." Sites that are owned and operated by health authorities have an advantage over stand-alone private and not-for-profit facilities in that they have access to additional staff.

We would expect that the ratio of staff to patients would have an impact on quality of care; the role of government should be to determine an adequate funding level for the desired staffing ratio and then to provide it to all sites, regardless of whether they are run by for-profit or not-for-profit agencies.

\section{Ed Helfrich}

Chief Executive Officer

BC Care Providers Association

Vancouver, BC

\section{REFERENCE}

I. McGrail KM, McGregor MJ, Cohen M, et al. Forprofit versus not-for-profit delivery of long-term care. CMAJ 2007;176:57-8.

DOI:I0.I503/cmaj.I070025

\section{[Two of the authors respond:]}

We are in agreement with many, but not all, of Ed Helfrich's points concerning our commentary. ${ }^{1}$ First, he acknowledges that there are differences in staffing levels between for-profit and not-for-profit long-term care facilities in British Columbia, something that we and others have found to be true. ${ }^{2,3}$ However, in saying that the prime reason for these differences is the variation in the amount of funding given to different types of facilities that care for similar patients, Helfrich describes the current situation, whereas the study we referred to in our commentary was based on data from the mid to late I99os, before the complex-care patient designation was introduced. Variation in current funding levels cannot be the reason for the differences in quality of care found in that study.

Second, Helfrich argues that the better performance of facilities operated by health authorities must be driven by those facilities' access to additional staff. This is precisely the point of our commentary. Surely it is quite feasible that different forms of ownership imply different types of access to resources; the important question is whether those resources make a difference. Do multisite not-for-profit facilities do better than single-site facilities because they can share the costs of developing policies and care practices? Or is it because they can share the costs of specialized staff, such as nurse geriatri- 